\title{
COMMENTARY
}

\section{Health care resource groups in accident and emergency medicine}

\author{
Nigel Brayley, Jonathan Marrow
}

The National Casemix Office (NCMO) has been set up by the Information Management Group of the NHS Management Executive. Its task is to develop a classification of the work of health care professionals in the NHS which reflects the amount of human and material resource used in the care of widely varying conditions. Diagnostic related groups (DRGs) have been developed in the United States of America for this purpose but they are difficult to apply in the United Kingdom. ${ }^{1}$ Health care resource groups (HRGs) are being developed by the NCMO to function specifically in the context of the NHS. ${ }^{2}$

Groupings are very much specific to each specialty, and the huge diversity of work we undertake in accident and emergency (A\&E) departments at first seems particularly challenging. The British Association for Accident and Emergency Medicine has set up a group to work with staff from the NCMO in trying to develop a practical way of measuring the work we do, from the point of view of resource use (see appendix).

Until we have such a measure, it is very difficult to compare the work of one department with that of another, or to identify the effect of changes in work pattern in one department over the course of time. DRGs were developed in an insurance based system of health care provision in the USA and have been found to be of use there. There is need for such measures in a publicly funded health system also, to ensure that equipment and staff are allocated according to the level of work. HRGs should not be seen as a threat but as a central item of information in the running of our service.

Detailed work in Australia has shown that urgency of need for treatment, expressed as a triage code, relates closely to resource use. ${ }^{3}$ The case mix measure may thus be closely related to the triage scale. Development of this case mix measure has run parallel with agreement on a nationally accepted triage scale in Australia and New Zealand, but we have not yet reached that in the United Kingdom.

The Australian work also considered a case mix measure based on coding which identifies actual diagnoses or groups of diagnoses. There were over 200 points on the scale and it still only related approximately to the level of resources used. Another practical measure which correlated with resource use was based on what happens to each patient at the end of their care in the A\&E department - outcome of attendance or, rather inelegantly, "disposal."

This measure seems particularly attractive because most departments already count patients who are admitted, patients discharged, and patients referred to formal outpatient clinics, so that the proposed scale will not place new heavy demands on already strained record systems.

We have up to now quoted valuable work done in Australia ${ }^{3}$ but it is important to ensure that any measure we introduce in this country is valid in the circumstances of our work here. A study of 3200 episodes at Colchester General Hospital was made in 1992 with support from the Department of Health. ${ }^{4}$ Every aspect of the care of each patient was measured, including the amount of staff time involved. This study does support the use of outcome, or disposal, as having good predictive value of level of resource use. Remarkably, even this very simple measure is actually substantially better than the case mix measures so far worked out for several other major specialties in the United Kingdom.

We are currently seeking to validate our proposed scale further, using data from other departments where much information is recorded about the way resources are used.

The scale is likely to expressed as follows:

- Discharged/referred to general practitioner

- Referred to outpatient clinic (including A\&E clinic)

- Admitted (includes GP heralded admissions where these are cared for in A\&E department, and also transfers to other hospital)

- Deaths in department

The scale is simply an expression of relative values at the moment. We cannot say reliably how much the care of each patient in each group should be. We need to have a lot more costed data to give any idea about that. Eventually we hope that it may be possible to derive actual values from the case mix measure so that valid calculations to support budgetary needs can be made on the basis of known workload data.

We recognise that the data on which our suggestion is made are derived from departments where patients from a mixed age range are treated. We are uncertain of the validity of this scale in predominantly 
paediatric departments. More work is required for application to the care of observation ward patients and, for that matter, to that of patients waiting for long periods in the $A \& E$ department before admission.

The team from the National Case Mix Office needs help from departments with detailed resource use data suitable for analysis. We would also like to see a uniform triage scale in use, as it may be possible to improve discrimination of the case mix measure by introducing a further breakdown according to urgency. The Clinical Services Committee of the British Association for Accident and Emergency Medicine is seeking to develop an acceptable triage scale for use in this country. A further useful measure may be derived from data about procedures used in the care of particular patients. The project is continuing and we hope for the support of colleagues both in volunteering useable data about the work of their departments and in being willing to pilot our initial casemix scale, when it becomes available.
Appendix

The members of the Accident and Emergency Medicine Casemix Working Group:

For the BAEM:

- Mr Jonathan Marrow, Merseyside (chair)

- Mr Nigel Brayley, Colchester (lead clinician)

- Dr John Gosnold, Hull

- Mr Peter Freeland, West Lothian

- Mr Stephen Miles, London

\section{For the NCMO:}

- Dr Hugh Sanderson (Director of NCMO)

- Mr Phil Anthony (statistical advisor)

- Ms Penny Bray (project manager)

- Ms Lisa Blayden (statistical advisor)

1 Sanderson H, Storey A, Morris D, McNay R, Robson M, Loeb J. Evaluation of diagnosis related groups in the National Health Service. Community Med 1989; 11:269-78.

2 Buckland RW. Healthcare resource groups: a more sensitive and less costly approach to contracting. $B M F 1994 ; 308$. 1056

3 Jelinek J. A casemix information system for Australian hospital emergency departments. Report to the Commissioner of emergency departments. Report to the Commissioner of
Health, Health Department of Western Australia, Perth,

1992.
4 Brayley N. Iso-resource grouping project. Final report to the Department of Health, 1993. (Unpublished research findings. Data obtainable from the author.)

\title{
The Faculty of Accident and Emergency Medicine
}

\section{SPECIALTY EXAMINATION}

The first Faculty specialty examination in accident and emergency medicine will be held on 3/4 October 1996 at the Royal College of Physicians and Surgeons of Glasgow.

Regulations and application forms are available from:

\author{
The Secretariat \\ Intercollegiate Specialty Boards \\ 3 Hill Square \\ Edinburgh \\ EH8 (DR
}

Tel: 01316629222

Fax: 01316629444

The closing date for receipt of applications is

9 August 1996

Fee $-£ 500$ 